\title{
NACA 2415- FINDING LIFT COEFFICIENT USING CFD, THEORETICAL AND JAVAFOIL
}

\author{
Sarfaraj Nawaz Shaha ${ }^{1}$, M. Sadiq A. Pachapuri

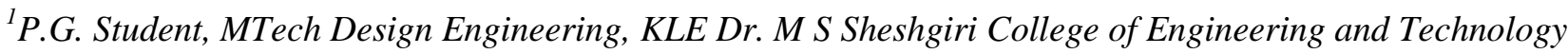 \\ (KLECET), Karnataka, India \\ ${ }^{2}$ Professor, MTech Design Engineering, KLE Dr. M S Sheshgiri College of Engineering and Technology (KLECET), \\ Karnataka, India
}

\begin{abstract}
In this paper we have studied the experimental characteristic graph of NACA 2415.The experimental graphs were taken from the book, "Theory of wing section" by IRA H. ABBOTT. We used these graphs for the validation of our results. Then we use CFD to simulate the experimental flow conditions and check the results and compare them with the experimental results. We meshed the airfoil in ICEM CFD so that the meshing is very precise.

We then calculate the NACA 2415 airfoil's lift at different angle of attack theoretically and using CFD analysis and compare them with the experimental values. We find the errors between experimental and CFD values as well as experimental and theoretical values. We used another simulation software called Javafoil and used it for comparison.
\end{abstract}

Keywords: Experimental, CFD, Theoretical, Javafoil

\section{INTRODUCTION}

Airfoil design plays a very important role in the desing of wings as many factors are dependent on it like the shape of the airfoil decides the amount of lift that will be generated by it and the drag force and many other things. There are many types of airfoil designs available like Clark Y, NACA, NASA GA (W) etc out of which the NACA airfoils are the most standard airfoils used in preliminary design and which are modified later for their specific use. In this paper we are going to study about the NACA 2415 airfoil design.

\subsection{Geometric Characteristics of Airfoils [1]}

These geometric characteristics help us to study the airfoil and hence are very important while deciding the airfoil shape.

Figure shows typical experimental characteristics of an airfoil. The features of the three plots in this figure can be briefly described as follows:

1) Lift coefficient $\left(C_{\mathbb{l}}\right)$ vs angle of attack $(\alpha)$. This curve, shown in Figure below, has four important features viz.

(a) Angle of zero lift ( $\left.\alpha_{01}\right)$

(b) Slope of the lift curve denoted by $\mathrm{d} C_{\mathbb{l}} / \mathrm{d} \alpha$ or $a_{0}$ or $C_{\mathbb{l} a}$

(c) Maximum lift coefficient $\left(C_{\ln a x}\right.$ ) and

(d) Angle of attack ( $\left.\alpha_{\text {stall }}\right)$ corresponding to $C_{\text {Imax }}$
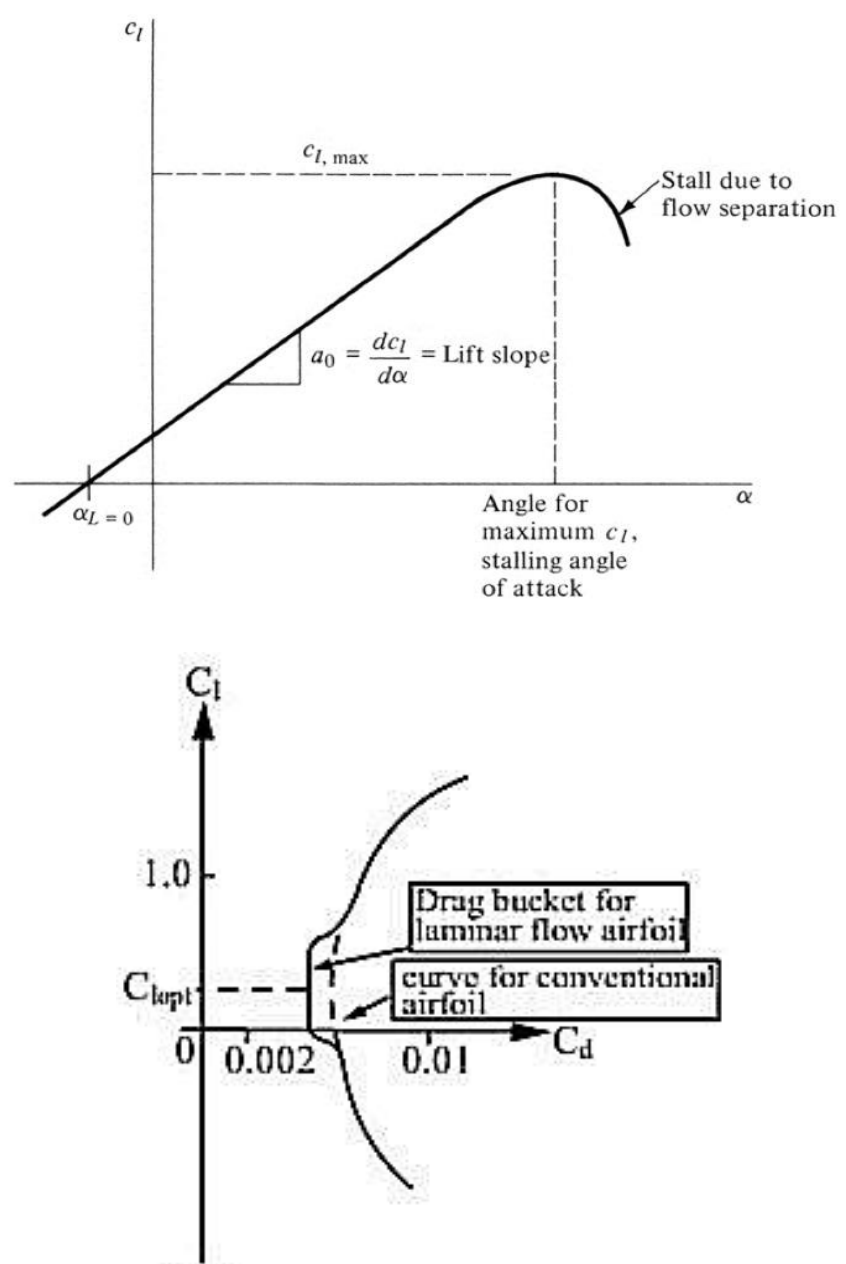

(b) 


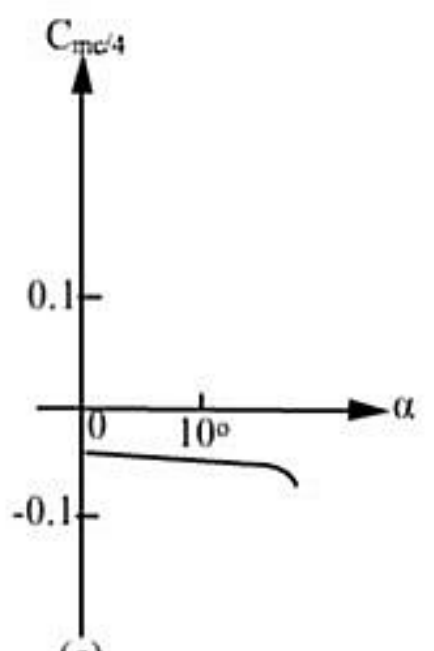

(c)

Drag coefficient $\left(C_{\mathfrak{l}}\right)$ vs $C_{\mathbb{l}}$. This curve, shown in Fig b, has two important features viz.

(a) Minimum drag coefficient $\left(C_{d \min }\right)$ and

(b) Lift coefficient $C_{\text {lopt }}$ corresponding to $C_{\text {dmin }}$.

In some airfoils, called laminar flow airfoils or low-drag airfoils, the minimum drag coefficient extends over a range of lift coefficients (Fig.b). This feature is called 'Drag bucket'. The extent of the drag bucket and the lift coefficient at the middle of this region are also characteristic features of the airfoil. It may be added that the camber decides $C_{\text {lopt }}$ and thickness ratio decides the extent of the drag bucket.

Pitching moment coefficient about quarter-chord Cmc/4 vs $\alpha$. This curve is shown in Fig c. Sometimes this curve is also plotted as $C_{\text {me/4 }}$ vs $C_{\mathbb{l}}$. From this curve, the location of the aerodynamic center (a.c.) and the moment about it ( $\left.C_{\text {mac }}\right)$ can be worked out. It may be recalled that a.c. is the point on the chord about which the moment coefficient is independent of $C_{\mathbb{l}}$.

Stall pattern: Variation of the lift coefficient with angle of attack near the stall is an indication of the stall pattern. A gradual pattern as shown in Fig a is a desirable feature. Some airfoils display abrupt decrease in $C_{\mathbb{l}}$ after stall. This behaviour is undesirable as pilot does not get adequate warning regarding impending loss of lift. Airfoils with thickness ratio (t/c) between $6-10 \%$ generally display abrupt stall while those with $\mathrm{t} / \mathrm{c}$ more than $14 \%$ display a gradual stall. It may be added that the stall patterns on the wing and on the airfoil are directly related only for high aspect ratio ( $\mathrm{A}>6)$ unswept wings.

\section{EXPERIMENTAL RESULTS [2]}

Below shown is the experimental data plotted for NACA 2415 airfoil. The graph shows how coefficient of lift and moment coefficient varies with angle of attack of the airfoil. This is an important characteristic graph as it tells us what will the maximum coefficient of lift provided.
Usually the coefficient of lift provided by the un cambered airfoil is different from that of the cambered airfoil. The lift coefficient is zero at zero angle of attack whereas for cambered airfoil this is not the case as we can see from the graph shown below. The NACA 2415 (which has a camber of $15 \%$ ) provides 0.21 of lift coefficient at zero angle of attack. This means that their will some lift provided at zero angle of attack where in uncambered airfoil the lift would be zero. The maximum lift coefficient is 1.41 provided at 13.965 degrees after this the airfoil stalls and there is sudden dip in lift coefficient which can be dangerous. Hence the maximum value of fin angle of attack is limited to 13.965 degrees.

The second plot is between the angle of attack and the moment coefficient which remains constant for most of the value of angle of attack of the airfoil.

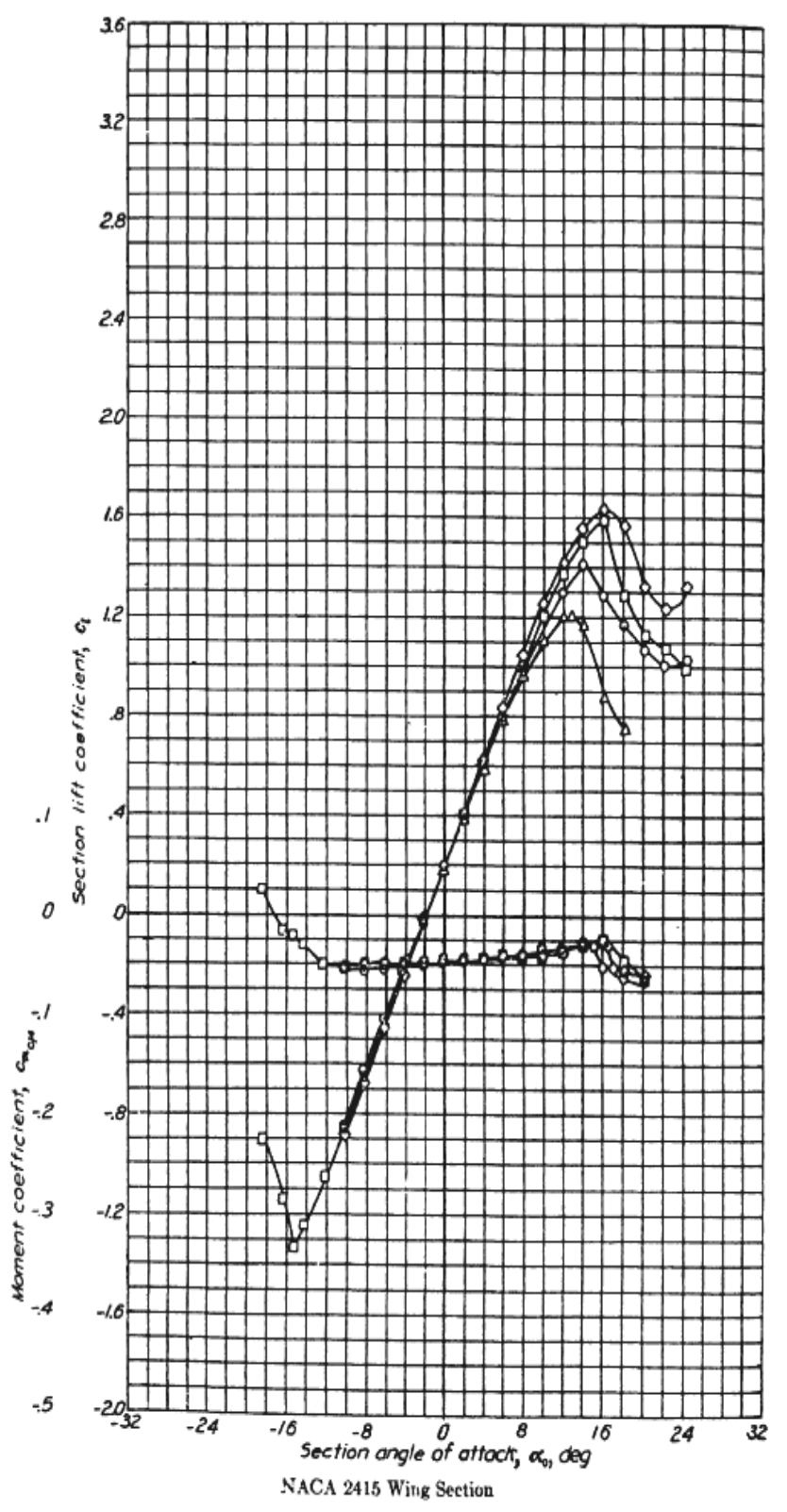


Table -1: Experimental Data of NACA 2415

\begin{tabular}{|l|l|}
\hline $\begin{array}{l}\text { Experimental Lift } \\
\text { Coefficient, Cl }\end{array}$ & $\begin{array}{l}\text { Experimental Angle of } \\
\text { Attack (Degrees) } \alpha\end{array}$ \\
\hline-0.8384253088065412 & -9.74910394265233 \\
\hline-0.7513818537278958 & -8.996415770609318 \\
\hline-0.6941615569181554 & -8.444444444444445 \\
\hline-0.6244912467786365 & -7.741935483870968 \\
\hline-0.5896738647471782 & -7.4408602150537675 \\
\hline-0.5001510708255577 & -6.688172043010752 \\
\hline-0.41558695458988737 & -5.935483870967744 \\
\hline-0.3459166444503694 & -5.232974910394262 \\
\hline-0.28619923575935324 & -4.630824372759861 \\
\hline-0.21656447169643656 & -4.028673835125453 \\
\hline-0.15185283924286885 & -3.3261648745519707 \\
\hline-0.10208833200035583 & -2.8243727598566295 \\
\hline-0.04237092330933967 & -2.2222222222222214 \\
\hline 0.02230516306762631 & -1.6200716845878205 \\
\hline 0.09193992713054255 & -1.0179211469534124 \\
\hline 0.1616102372700614 & -0.3154121863799304 \\
\hline 0.23620367901892836 & 0.28673835125447766 \\
\hline 0.2860037323380431 & 0.8888888888888857 \\
\hline 0.34568559495245754 & 1.390681003584227 \\
\hline 0.41039722740602524 & 2.093189964157702 \\
\hline 0.5048609259752954 & 2.7956989247311768 \\
\hline 0.6044610326135254 & 4 \\
\hline 0.7088776326312982 & 4.802867383512542 \\
\hline 0.79848929174444242 & 5.806451612903217 \\
\hline 0.8532835688260909 & 6.508960573476699 \\
\hline 0.9030836221452057 & 7.111111111111107 \\
\hline 0.9428952279392164 & 7.512544802867382 \\
\hline 0.9976184128676797 & 8.014336917562716 \\
\hline 1.0424242424242425 & 8.516129032258064 \\
\hline 1.0773127166089043 & 9.017921146953405 \\
\hline 1.1022127432684462 & 9.318996415770606 \\
\hline 1.1371012174531234 & 9.820788530465947 \\
\hline 1.1769128232471342 & 10.2222222222222221 \\
\hline 1.2043455078645695 & 10.673835125448015 \\
\hline 1.2416955478539058 & 11.125448028673837 \\
\hline
\end{tabular}

\begin{tabular}{|l|l|}
\hline 1.2765840220385676 & 11.627240143369171 \\
\hline 1.301484048698125 & 11.928315412186372 \\
\hline 1.3314493912734382 & 12.530465949820787 \\
\hline 1.3563849640095977 & 12.931899641577054 \\
\hline 1.3863147605083088 & 13.433691756272395 \\
\hline 1.4162445570070203 & 13.93548387096773 \\
\hline 1.376859504132232 & 14.738351254480285 \\
\hline 1.337438905180841 & 15.440860215053753 \\
\hline 1.2930596285434999 & 16.143369175627228 \\
\hline 1.2535679374389055 & 16.645161290322577 \\
\hline 1.219070470096863 & 17.247311827956985 \\
\hline
\end{tabular}

The next graph shows the plot of coefficient of lift versus coefficient of drag and coefficient of moment for different Reynolds number. Following conclusions can be drawn from the graphs:

The plot between coefficient of lift and coefficient of drag tells us that the lift coefficient is a function of Reynold's number as well as angle of attack. Hence as the Reynolds number increases the lift coefficient will increase. We also notice that the coefficient of drag is more initially when the lift coefficient is negative and decreases as the lift coefficient approaches zero and as the lift continues to increase and become more positive there is a steep increase in drag coefficient also.

The second plot in the same graph is between lift coefficient and moment coefficient. As we see that the moment remains constant for throughout for any value of lift and coefficient and hence will remain constant at all angle of attack 

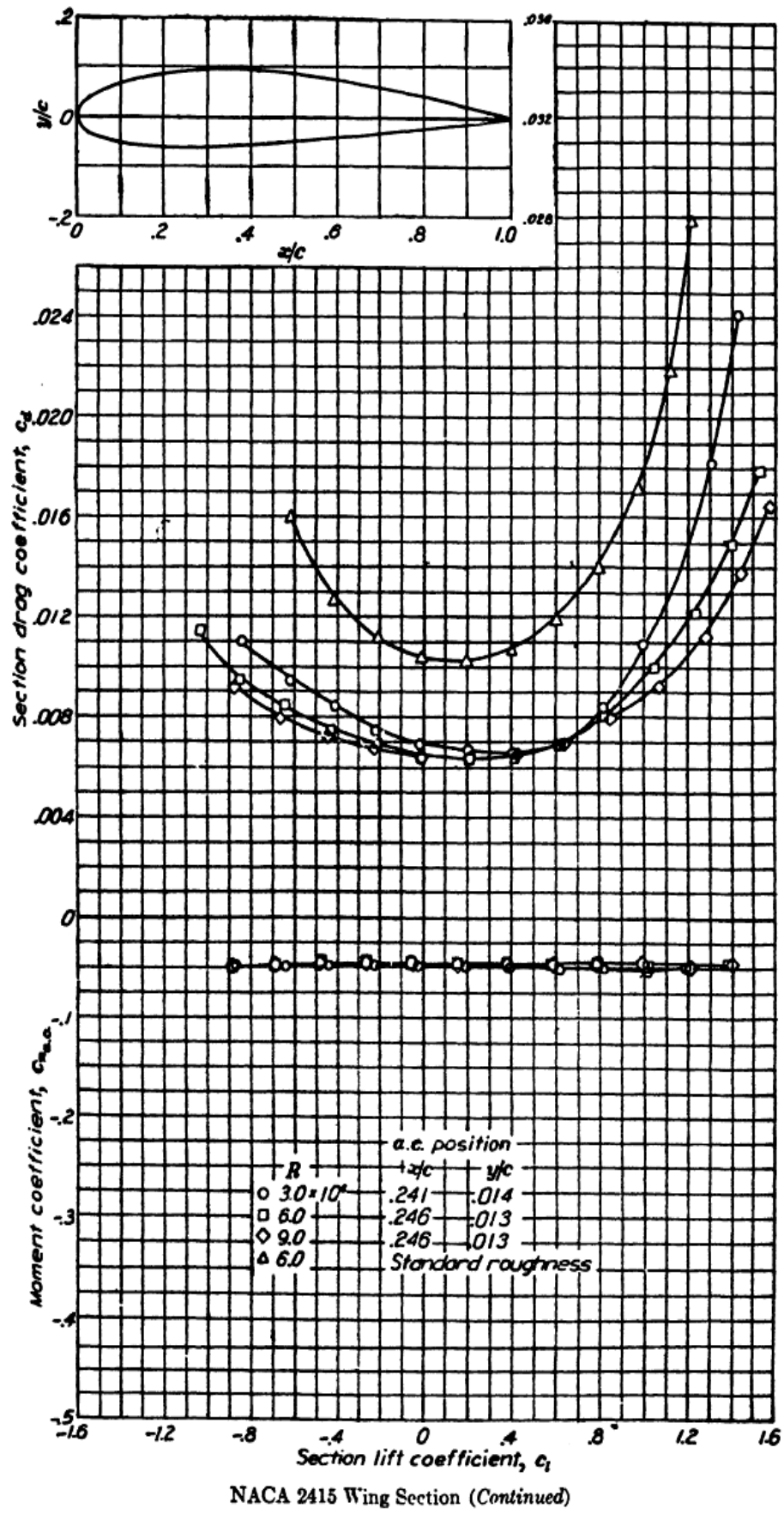

\section{THEORETICAL ANALYSIS [3]}

Sighard F. Hoerner found empirical formulas for finding out the lift coefficient at different angle of attacks for a cambered airfoil design.

At zero angle of attack i.e. when $\alpha=0$ the lift coefficient is given by the relation:

$$
c_{\mathrm{l}}=4 \pi(f / c)
$$

Since for cambered airfoils the lift coefficient is not zero at zero angle of attack. The angle of attack at which the lift coefficient becomes zero is given by the formula:
$C_{l}=0$ at

$\alpha_{0}=-1.15(f / c) \%$ degrees

Where $f / c=$ camber ratio

Maximum lift us given by the relation:

$$
C_{\mathrm{I}}=\frac{A R(f / c)}{\left(\frac{0.25}{\pi}\right)}
$$

$\mathrm{AR}=$ Aspect ratio of wing (Usually aspect ratio=6)

\begin{tabular}{|c|c|}
\hline $\begin{array}{l}\text { Theoretical angle of } \\
\text { attack, } \alpha\end{array}$ & $\begin{array}{ll}\text { Theoretical } & \text { Lift } \\
\text { Coefficient, } C_{\mathbb{l}} & \end{array}$ \\
\hline-3 & -.0763 \\
\hline-2.3 & 0 \\
\hline-2 & .0328 \\
\hline-1 & .1419 \\
\hline 0 & 0.251 \\
\hline 1 & 0.3601 \\
\hline 2 & 0.4692 \\
\hline 3 & 0.5783 \\
\hline 4 & 0.6874 \\
\hline 5 & 0.7965 \\
\hline 6 & 0.9065 \\
\hline 7 & 1.0147 \\
\hline 8 & 1.1238 \\
\hline 9 & 1.2329 \\
\hline 10 & 1.342 \\
\hline 11 & 1.4511 \\
\hline 12 & 1.5602 \\
\hline 13 & 1.6693 \\
\hline 14 & 1.7784 \\
\hline 15 & 1.8875 \\
\hline
\end{tabular}

Table -2: Theoretical Data of NACA 2415

From the above calculations we can see that the lift coefficient keeps on increasing linearly with angle of attack. But this is not so. Hence this method cannot be relied for finding out lift coefficient as it will not tell us about the stalling point. 


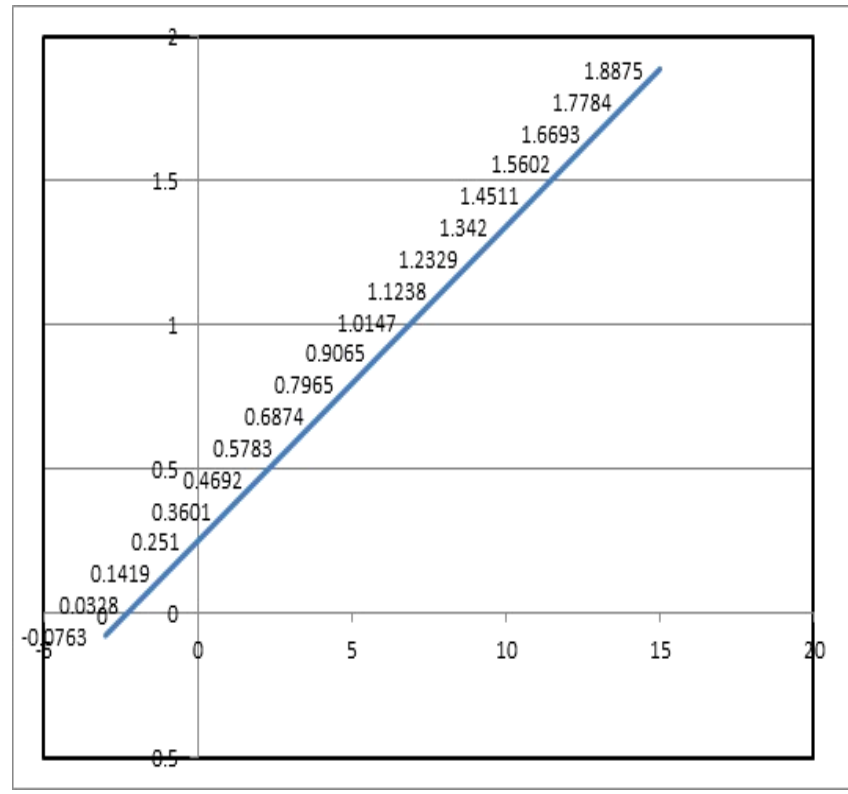

Theoretical lift coefficient vs Theoretical angle of attack

\section{CFDANALYSIS}

\subsection{Meshing}

Table -3: CFD Data of NACA 2415

\begin{tabular}{|l|l|}
\hline angle of attack, $\alpha$ & Lift Coefficient, $C_{\mathfrak{l}}$ \\
\hline-20 & -0.548712 \\
\hline-18 & -0.5394 \\
\hline-16 & -0.5247 \\
\hline-14 & -0.531175 \\
\hline-12 & -0.5748 \\
\hline-10 & -0.57079 \\
\hline-8 & -0.52233 \\
\hline-6 & -0.3821 \\
\hline-4 & -0.1977 \\
\hline-2 & -0.0549 \\
\hline 0 & 0.247 \\
\hline 2 & 0.150 \\
\hline 4 & 0.658 \\
\hline 6 & 0.75712 \\
\hline 8 & 0.927 \\
\hline 10 & 1.0613 \\
\hline 12 & 1.2103 \\
\hline 14 & 1.277 \\
\hline 16 & 0.891007 \\
\hline 18 & 0.873 \\
\hline
\end{tabular}

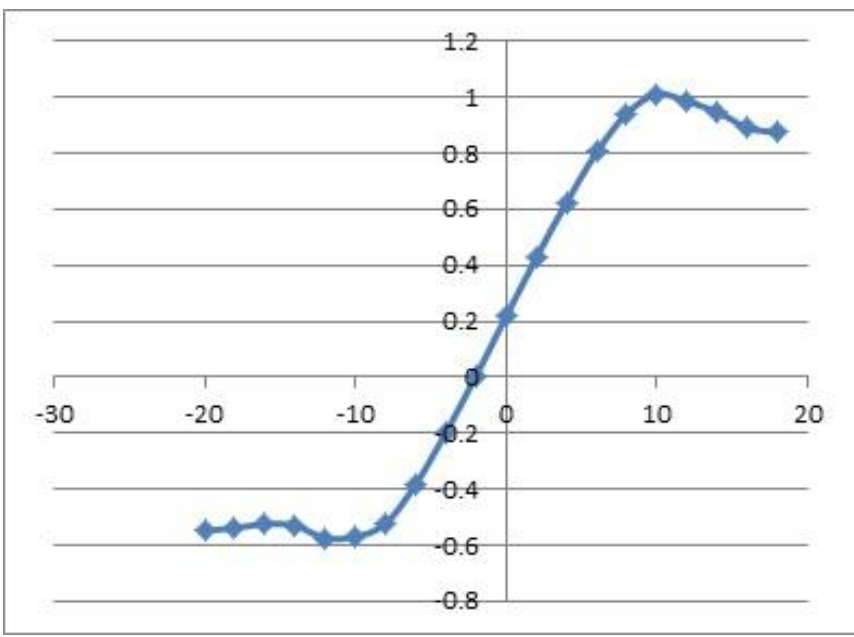

CFD angle of attack vs lift coefficient

\section{JAVAFOIL ANALYSIS}

Table -4: Javafoil Data of NACA 2415

\begin{tabular}{|llllll|}
\hline$\alpha$ & $\mathrm{Cl}$ & $\mathrm{Cd}$ & $\mathrm{Cm} 0.25$ & $\mathrm{Cp}$ & $\mathrm{M}$ cr. \\
\hline$\left.{ }^{\circ}\right]$ & {$[-]$} & {$[-]$} & {$[-]$} & {$[-]$} & {$[-]$} \\
\hline-10.0 & -0.737 & 0.07128 & -0.020 & -4.888 & 0.343 \\
\hline-9.0 & -0.675 & 0.05437 & -0.026 & -4.162 & 0.366 \\
\hline-8.0 & -0.657 & 0.02669 & -0.035 & -3.481 & 0.394 \\
\hline-7.0 & -0.572 & 0.02236 & -0.038 & -2.846 & 0.426 \\
\hline-6.0 & -0.461 & 0.01987 & -0.040 & -2.291 & 0.463 \\
\hline-5.0 & -0.343 & 0.01667 & -0.042 & -1.837 & 0.501 \\
\hline-4.0 & -0.223 & 0.01828 & -0.043 & -1.415 & 0.546 \\
\hline-3.0 & -0.101 & 0.01786 & -0.045 & -1.081 & 0.593 \\
\hline-2.0 & 0.022 & 0.01723 & -0.047 & -0.798 & 0.644 \\
\hline-1.0 & 0.146 & 0.01640 & -0.049 & -0.586 & 0.692 \\
\hline-0.0 & 0.269 & 0.01554 & -0.051 & -0.687 & 0.667 \\
\hline 1.0 & 0.391 & 0.01560 & -0.052 & -0.806 & 0.642 \\
\hline 2.0 & 0.512 & 0.01797 & -0.054 & -0.950 & 0.615 \\
\hline 3.0 & 0.633 & 0.01860 & -0.056 & -1.139 & 0.583 \\
\hline 4.0 & 0.751 & 0.01953 & -0.058 & -1.399 & 0.548 \\
\hline 5.0 & 0.868 & 0.02083 & -0.059 & -1.735 & 0.511 \\
\hline 6.0 & 0.980 & 0.02222 & -0.061 & -2.138 & 0.475 \\
\hline 7.0 & 1.087 & 0.02507 & -0.063 & -2.633 & 0.440 \\
\hline 8.0 & 1.185 & 0.02836 & -0.064 & -3.161 & 0.410 \\
\hline 9.0 & 1.273 & 0.03183 & -0.065 & -3.806 & 0.381 \\
\hline 10.0 & 1.346 & 0.03614 & -0.066 & -4.530 & 0.353 \\
\hline 11.0 & 1.401 & 0.04250 & -0.066 & -5.301 & 0.331 \\
\hline 12.0 & 1.429 & 0.05369 & -0.065 & -6.118 & 0.310 \\
\hline 13.0 & 1.399 & 0.08199 & -0.058 & -6.980 & 0.293 \\
\hline 14.0 & 1.379 & 0.11282 & -0.046 & -7.887 & 0.277 \\
\hline & & & & & \\
\hline
\end{tabular}




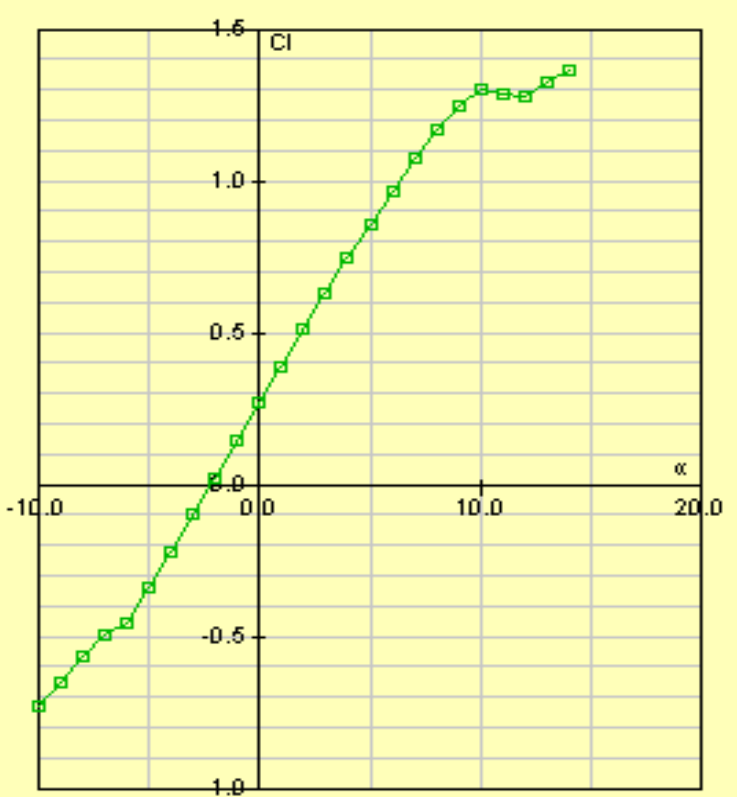

Angle of attack vs Lift coefficient

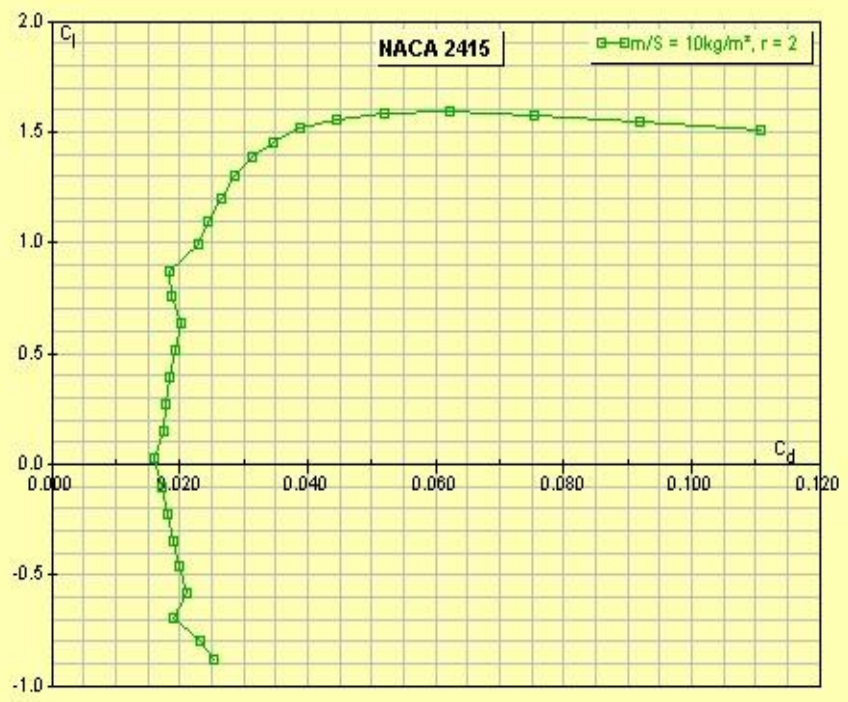

Drag coefficient vs lift coefficient

\section{COMPARISON}

Now we comparing software and theoretical results with the experimental results:

Table -5: Error percentage

\begin{tabular}{|l|l|l|l|l|}
\hline $\begin{array}{l}\text { Angle of } \\
\text { Attack } \\
\left(\begin{array}{l}\text { Degrees } \\
\alpha\end{array}\right.\end{array}$ & $\begin{array}{l}\text { Experimenta } \\
1 \quad \text { Lift } \\
\text { Coefficient, } \\
\mathrm{Cl}\end{array}$ & $\begin{array}{l}\text { Theoretical } \\
\text { Lift } \\
\text { Coefficient } \\
C_{l}\end{array}$ & $\begin{array}{l}\text { CFD } \\
\text { Analysis }\end{array}$ & Javafoil \\
\hline-2 & -0.04237 & 0.0328 & -.0549 & \\
\hline 0 & 0.236203 & 0.251 & 0.247 & 0.269 \\
\hline 4 & 0.604461 & 0.6874 & 0.658 & 0.751 \\
\hline 10 & 1.176912 & 1.342 & 1.0612 & 1.346 \\
\hline
\end{tabular}

Table -6: Error percentage

\begin{tabular}{|l|l|l|l|}
\hline $\begin{array}{l}\text { Angle of } \\
\text { Attack } \\
(\text { Degrees) } \alpha\end{array}$ & $\begin{array}{l}\text { Experimental } \\
\text { Lift Coefficient, } \\
\mathrm{Cl}\end{array}$ & $\begin{array}{l}\text { CFD } \\
\text { Analysis, Cl }\end{array}$ & \% Error \\
\hline 0 & 0.236203 & 0.247 & 4.3 \\
\hline 4 & 0.604461 & 0.658 & 8.1 \\
\hline 10 & 1.176912 & 1.0612 & 9.8 \\
\hline
\end{tabular}

\section{CONCLUSION}

We studied the experimental characteristics graphs i.e. lift coefficient vs drag coefficient and effect of angle of attack on lift and drag coefficient of NACA 2415. We found that the lift coefficient increases linearly with angle of attack upto a certain value and then dips suddenly. We also learnt that coefficient of moment remains almost constant with the angle of attack. We also saw that the drag coefficient is more initially and it decreases as it approaches zero angle of attack on further increasing the angle of attack the drag coefficient also increases almost at exponential rate.

We then calculated lift using theoretical, CFD and Javafoil and compared them with the experimental results. We have found the error with respect to the experimental results. We conclude that CFD values are the best and closest to the experimental values.

\section{REFERENCES}

[1]. Airplane design (Aerodynamics, Chapter 5) by Prof. E.G Tulapurkara

[2]. Theory of Wing Section by Ira H. ABBOTT

[3]. Fluid Dynamics Lift By SINGHARD F. HOERNER

[4]. Performance Analysis, by SADRAEY M. (Drag force and drag coefficient)

\section{BIOGRAPHIES}

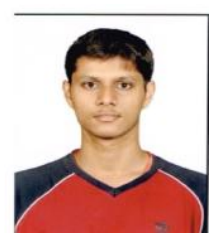

Sarfaraz Nawaz Shaha, Student MTech Design Engg, KLE Dr. M. S. Sheshgiri College of Engineering and Technology, Belgaum, Completed B.E. in Mechanical Engineering in 2012

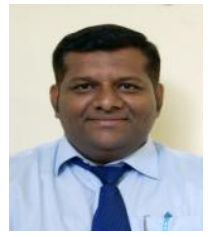

M. Sadiq A. Pachapuri, Assistant Professor, Department of Mechanical Engineering, KLE Dr. M. S. Sheshgiri College of Engineering and Technology, Currently Doing PhD, From VTU, Belgaum under Dr. S. F. Patil on topic "Design and Optimization of Flexural Bearings". Completed B.E. in Mechanical Engineering in 2009 and M.Tech. Design in 2011 from KLECET Belgaum. Also handling the exam section of KLECET from past 4 years 